\title{
Silicon Carbide MOSFETs in More Electric Aircraft Power Converters: The Performance and Reliability benefits over Silicon IGBTs for a specified Flight Mission Profile
}

\author{
Shane O'Donnell ${ }^{1,2}$, Jean-Louis Debauche ${ }^{1}$, Pat Wheeler ${ }^{2}$ and Alberto Castellazzi ${ }^{2}$ \\ ${ }^{1}$ MICROSEMI CORPORATION \\ ${ }^{2}$ UNIVERSITY OF NOTTINGHAM \\ Gort Road Business Park \\ Ennis, Co. Clare, Ireland \\ Tel: $+353(0) 656840044$ \\ Fax: +353 (0) 656822298 \\ sodonnell@microsemi.com \\ http://www.microsemi.com \\ University Park \\ Nottingham NG7 2RD, UK \\ Tel.: +44 (0) 1159515151 \\ Fax.: +44 (0) 1159513666 \\ http://www.nottingham.ac.uk/research/groups/power- \\ electronics-machines-and-control-group/index.aspx
}

\section{Acknowledgements}

The authors wish to acknowledge the support provided by the Microsemi Intelligent Power Solutions ${ }^{\mathrm{TM}}$ team.

\section{Keywords}

«Aerospace», «IGBT», «Intelligent Power Module (IPM)», «Mission Profile», «Modelling», «MOSFET», «Power semiconductor device», «Reliability», «Silicon Carbide (SiC)», «Systems engineering», «Wide bandgap devices».

\begin{abstract}
This paper describes the design, construction and performance of a $5 \mathrm{kVA}$ aviation power module containing silicon carbide MOSFETs. The function and control of this module within a commercial aviation power electrical control unit (ECU) application is explained and the power dissipation benefits from the use of these MOSFETs instead of silicon IGBTs when driving an electrical motor controlling an aileron are presented. The paper shows the calculated reliability figures for the power module in this application and an application-specific reliability test to verify 150,000 flight hours of module operation is introduced. Performance test results from a prototype unit are also presented.
\end{abstract}

\section{Introduction}

Wide bandgap semiconductor materials, such as silicon carbide ( $\mathrm{SiC})$, have properties which offer significant advantages over silicon ( $\mathrm{Si}$ ) in power converter applications. They offer improved power density, lower losses and operation at higher junction temperatures [1], [2], [3], [4], [5]. In applications such as commercial aviation, where size and weight are influencing factors, the emergence of SiC MOSFETs as alternatives to Si IGBTs has been extremely beneficial [6], [7], [8], [9] as power electronics become more essential in the More Electric Aircraft (MEA) development [10]. This paper presents the performance gains which can be achieved using SiC MOSFETs instead of the more traditional Si IGBTs in a $5 \mathrm{kVA}$ Power Core Module (PCM) designed specifically for motor drive applications such as primary flight control actuator systems, landing gear and braking systems in a more electric aircraft. The power module described herein uses $1200 \mathrm{~V}$ semiconductor devices with a $540 \mathrm{~V}$ DC bus which is being introduced in these newer generation aircraft.

Before any emerging technology is widely adopted in critical applications, its reliability and long-term performance must be proven. Mean Time Between Failure (MTBF) and Failure-in-Time (FIT) values 
are calculated for the power module containing SiC MOSFETs and an accelerated reliability test to verify long-term operation is described. In this paper, the power module design for an actuation system is presented and measured values from a prototype unit are used to validate the performance of the SiC MOSFET design in the intended application. Device mission models are described and the reliability calculations using the FIDES method [11] are presented. An accelerated reliability test to verify long-term performance is explained.

\section{Power Electrical Control Unit System}

The $5 \mathrm{kVA}$ PCM is an element of the Power Electrical Control Unit (ECU) or Power Drive Electronics (PDE) as shown in Fig. 1 [12]. The ECU also includes functionality for motor control, system health monitoring, filtering and protection.

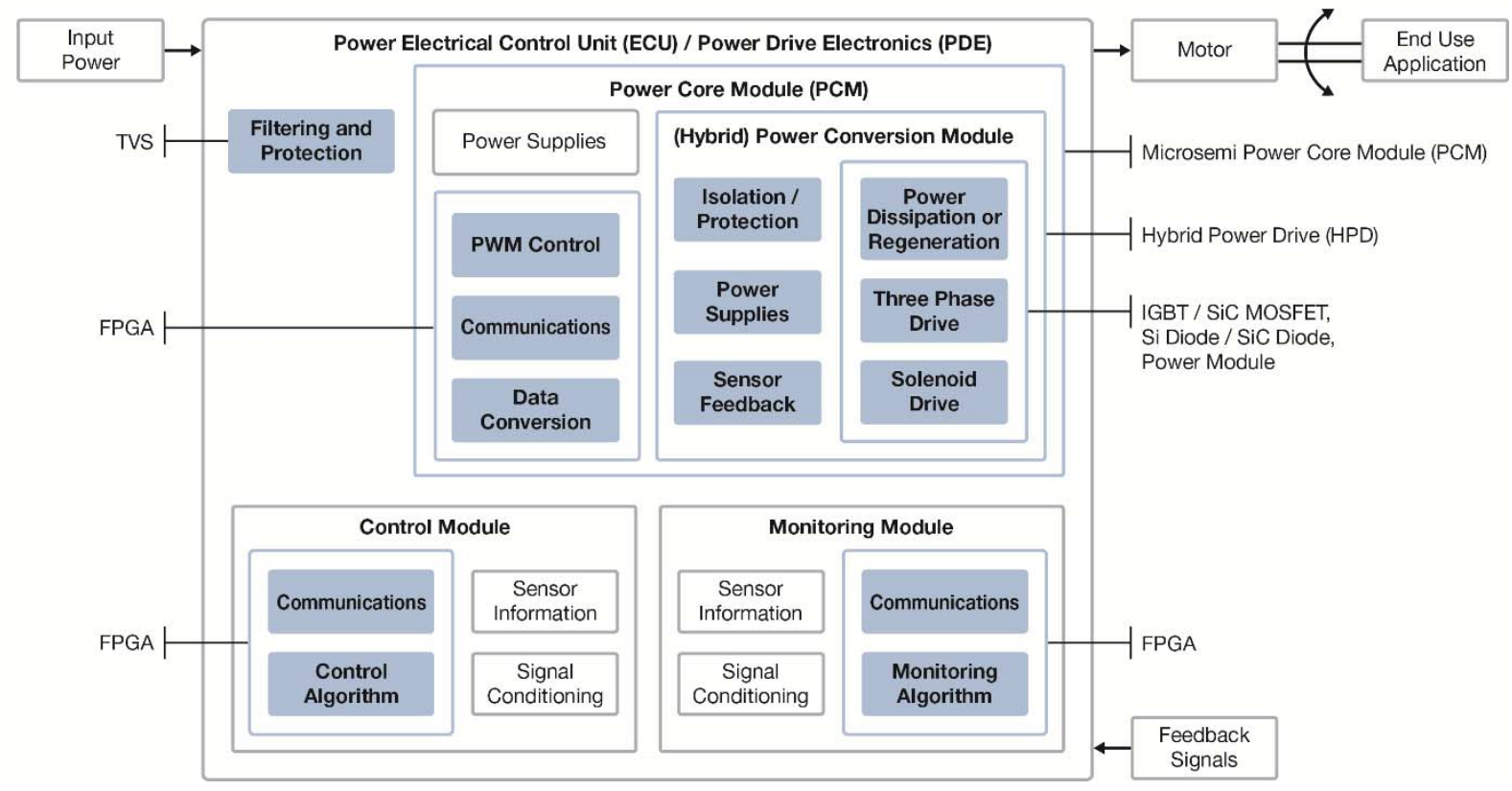

Fig. 1: Aviation Intelligent Power Electrical Control System

Using the aircraft data bus, the flight control computer sends the actuator commands to the control module which then issues motor control instructions to the PCM. The control module executes motor and control loop algorithms, which are described further later in this paper. The actuator performance is characterised from feedback signals to the monitoring module. The three modules communicate via a high-speed data bus.

\section{Power Core Module}

The printed circuit board (PCB) assembly visible in Fig. 2 comprises of a 6-layer PCB with local power supplies for the logic, signal conditioning circuitry for processing telemetry data and a military grade Microsemi A3P250 ProAsic3 FPGA [13] supporting communications, control and signal processing. This PCB, labelled the 'PCM controller' board interfaces with a 'driver' PCB though a board-to-board connector.

The gate drivers and associated circuitry are assembled on the driver board assembly. This PCB is an eight-layer design with double-sided component placement to minimise size and is connected to a substrate assembly through thermal, signal and power pins. The SiC MOSFETs [14], together with $\mathrm{SiC}$ anti-parallel diodes [15] and gate drive resistors are placed on this substrate which is soldered to 
an AlSiC base. This substrate assembly was produced by the Microsemi group in Bordeaux, France, using processes and construction materials currently used in production.

A Power Core Module is shown in Fig. 2 while the substrate assembly and construction are illustrated in Fig. 3 and Fig. 4 respectively.

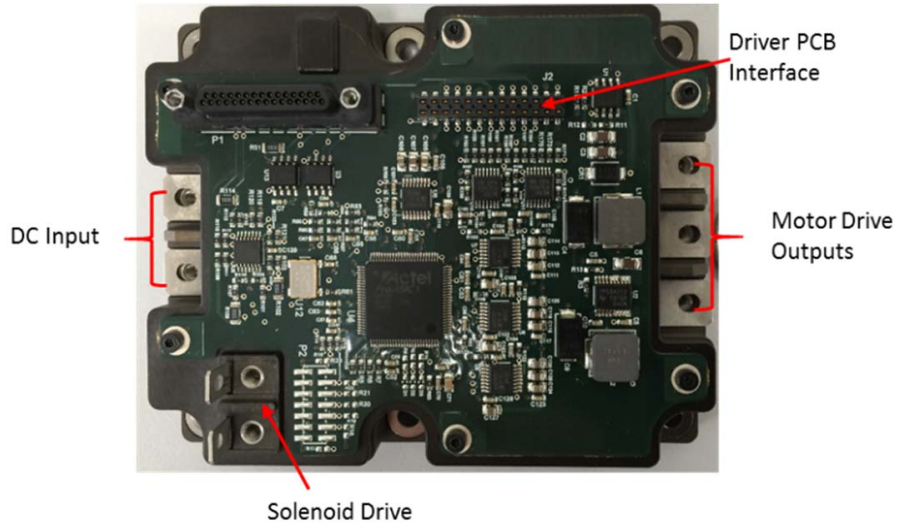

Fig. 2: Power Core Module

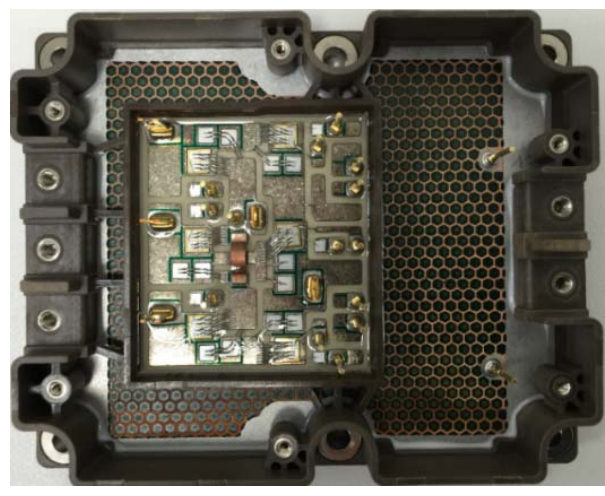

Fig. 3: Power substrate assembly

The 1200V SiC MOSFETs (or Si IGBTs) are connected in a typical 3-phase inverter bridge configuration as shown in Fig. 5. The 3-phase sinusoidal output is generated using PWM signals from the FPGA. In the circuit, an Infineon 1EDI60I12AF [16] is used as a gate drive for the SiC MOSFET while also providing input to output isolation voltage up to $1200 \mathrm{~V}$.

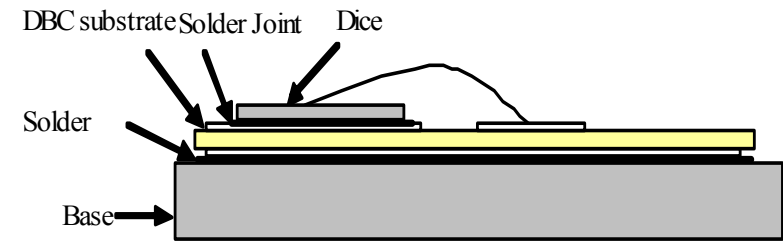

Fig. 4: Substrate construction

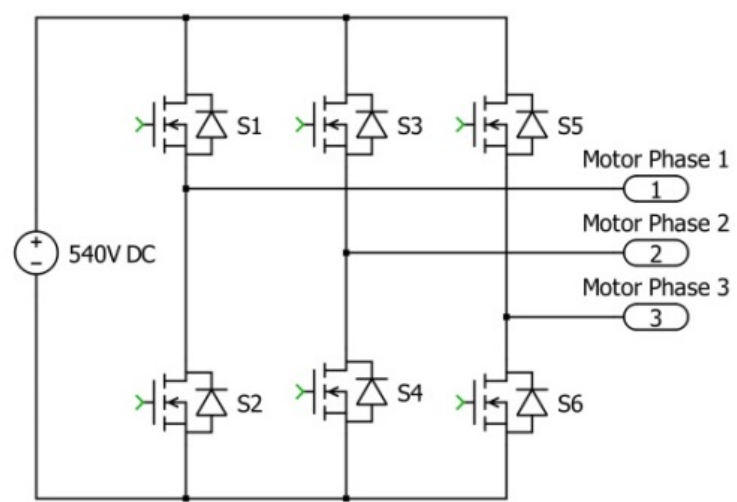

Fig. 5: Inverter circuit

Oscilloscope measurements showing the PWM and 3-phase current outputs, using 3mH inductors as the load, are shown in Fig. 6. The image displays a peak output current of 9A from a 540V input voltage. 


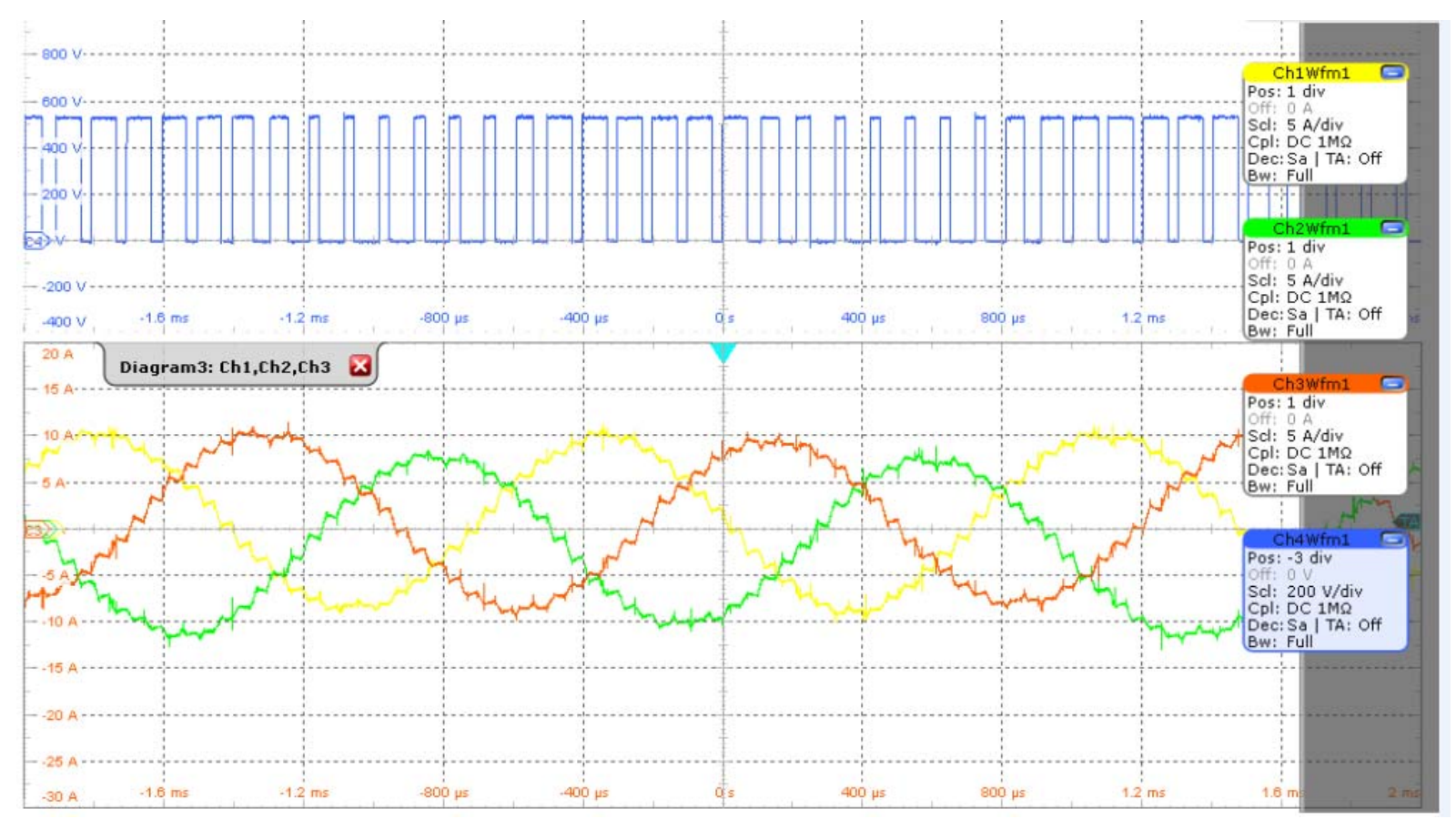

Fig. 6: PCM Measurements with inductive load

\section{Mission Modelling}

MathWork's MATLAB-Simulink software was used to create a simplified model, as shown in Fig. 7 and Fig 8, capable of translating flight characteristics into electrical and mechanical requirements for the actuation system. The actuator position command, from the flight controller, is the input to the model. The model contains three loops controlling the motor current, motor speed and actuator position, represented by the 'ki', 'komega' and ' $k x$ ' feedback elements respectively in Fig 8 . The output of 'Saturation1' represents the output current from the module to the DC equivalent motor while the 'Transfer Fcn' represents the inductance and resistance of the motor. The motor speed loop controls the stabilisation of the actuator and includes factors representing torque and inertia. The motor speed and actuator position loops were simulated to derive the output current requirements for the application.

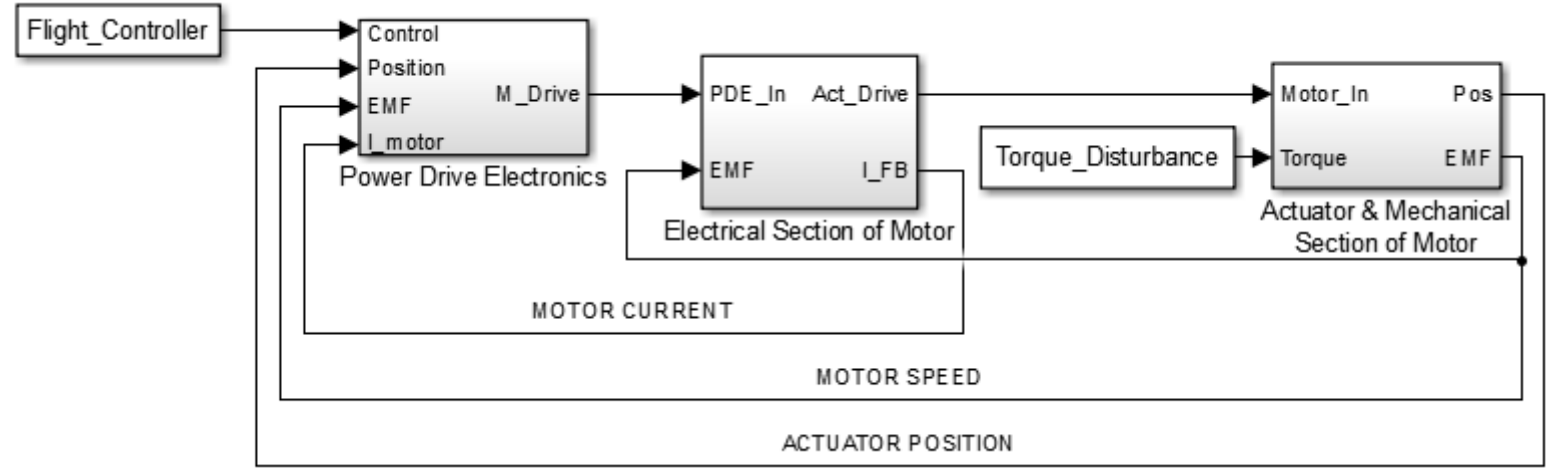

Fig. 7: Simulink sub-system model of actuation system 


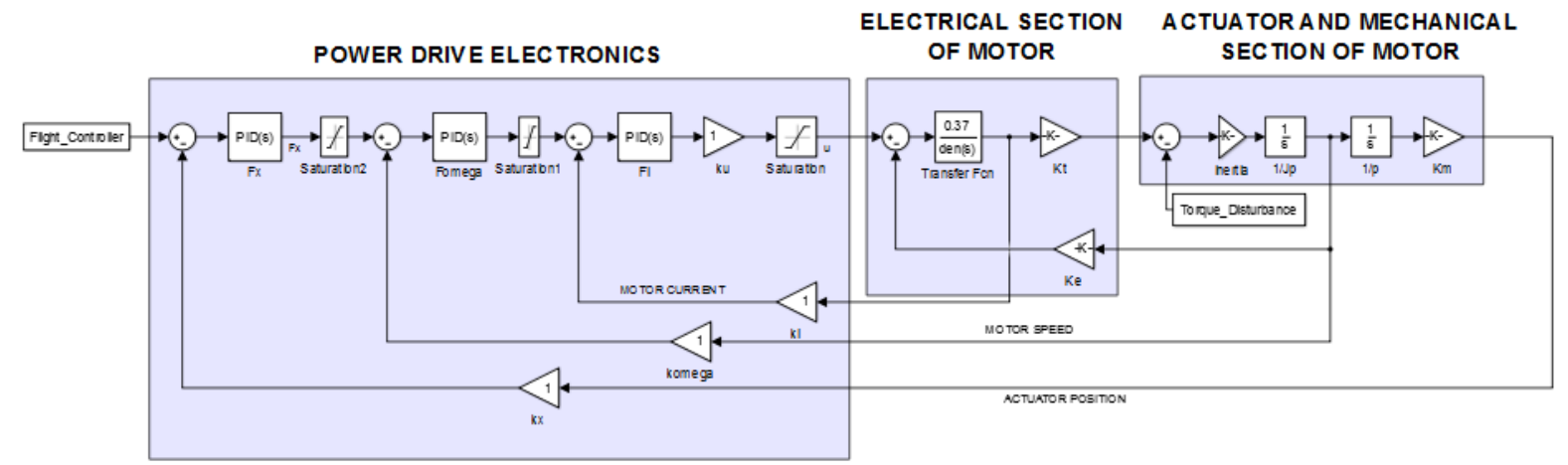

Fig 8: Detailed Simulink model of actuation system

The Iq values, which represent the equivalent output current from the motor to the actuator for the defined flight phases are plotted in Fig. 9. The polarity of the current represents the sign of the hinge moment with the value representing the aerodynamic effort during the flight.

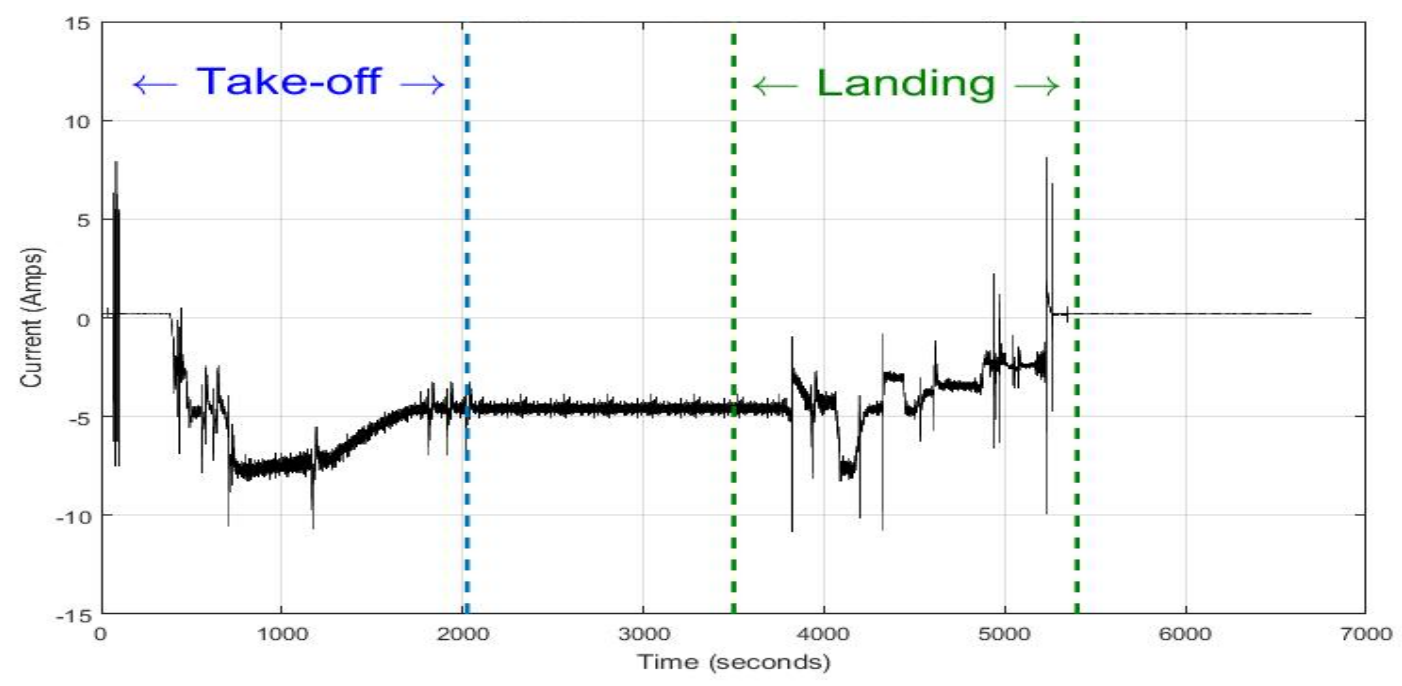

Fig. 9: Output current per flight phase

The hinge moment is effectively the force that must be overcome to deflect a control surface around the hinge line. This moment is primarily a function of the aerodynamic pressure difference between the upper and lower surfaces [17]. Fig. 10 [18] below illustrates the deflection angles in an aileron geometry, represented by $\delta$ Aup and $\delta$ Adown. A typical figure for the maximum deflection is 30 degrees [18].

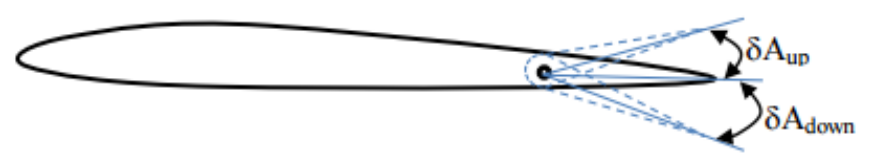

Fig. 10: Geometry of Aileron

The values of the corresponding maximum currents are calculated using Equation (1)

$$
\operatorname{Imax}=\operatorname{Iq} \times \frac{2}{\sqrt{3}}
$$

Using the mission model, the power losses at three different temperatures, scaled by the output current, in the substrate assembly are shown in Table I, while it is assumed the losses for the PCB 
assemblies remain constant and have been calculated at $4.63 \mathrm{~W}$ for the driver and $2.81 \mathrm{~W}$ for the PCM controller assemblies.

Table I: Substrate Assembly Power Losses

\begin{tabular}{|l|l|l|l|}
\hline $\begin{array}{l}\text { Current Level } \\
\text { (Amps Peak) }\end{array}$ & \multicolumn{4}{|l|}{ Total Converter Losses: 6 SiC MOSFET switches + diodes (W) } \\
\hline & $\mathrm{T}_{\mathrm{J}}=-55^{\circ} \mathrm{C}$ & $\mathrm{T}_{\mathrm{J}}=25^{\circ} \mathrm{C}$ & $\mathrm{T}_{\mathrm{J}}=125^{\circ} \mathrm{C}$ \\
\hline 12.5 & 40.34 & 17.50 & 20.96 \\
\hline 10.7 & 31.56 & 14.26 & 16.32 \\
\hline 8 & 19.78 & 10.20 & 11.42 \\
\hline 4.5 & 8.50 & 5.84 & 6.33 \\
\hline
\end{tabular}

The mission model was then used to calculate the junction temperatures of each component for the reliability analysis.

\section{Power dissipation comparison of SiC MOSFETS and Si IGBTs}

Using the criteria that the subsystems are located in an appropriately-sized enclosure which has two cooling surfaces, MATLAB software was also used to convert the actuation system's electrical and mechanical requirements obtained from the Simulink model into resultant skin temperatures. A review of the steady-state solution shows that even the moderate increase in power dissipation levels for the IGBT configuration result in skin temperatures approximately $40{ }^{\circ} \mathrm{C}$ higher than those for a $\mathrm{SiC}$ 3-phase bridge. Fig. 11 displays how the time dependent power dissipations and the constant power level compare for the two solutions over a typical flight.

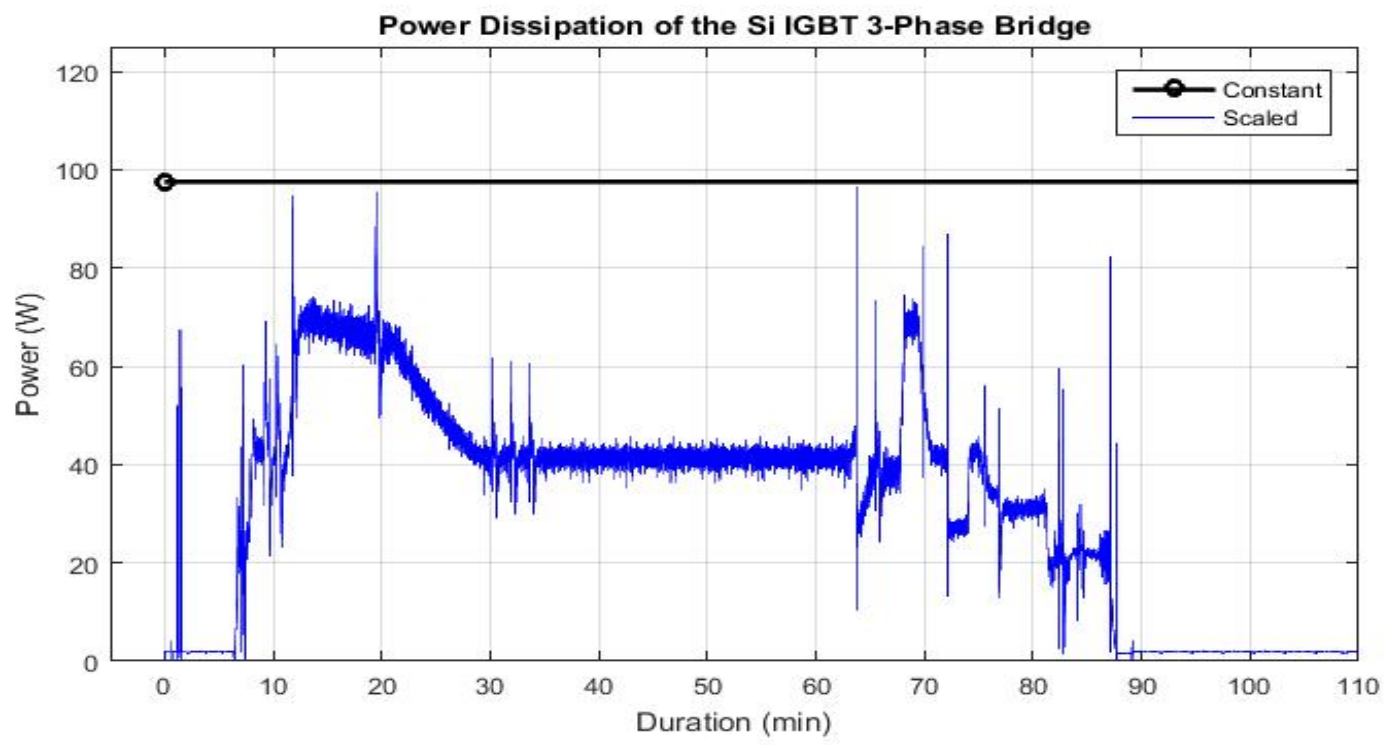




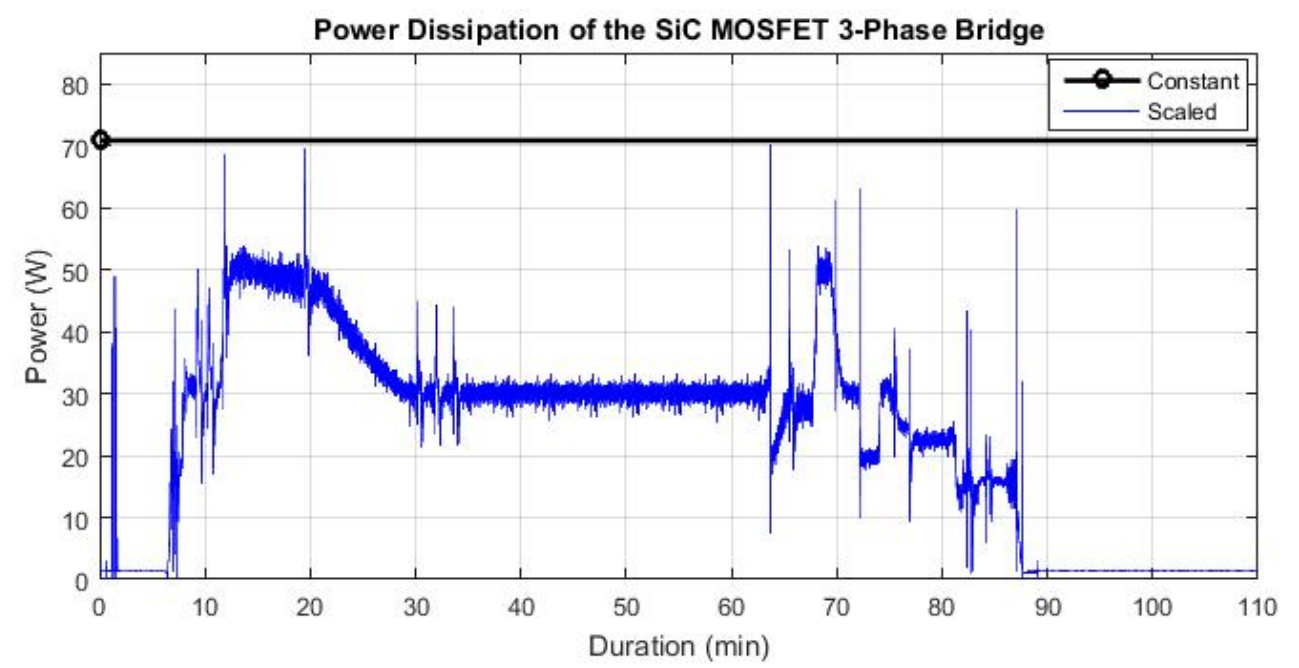

Fig. 11: Power dissipations of Si IGBT and SiC MOSFET design

\section{Reliability Calculations using Aircraft Life Cycles}

There are various standards and methods for predicting the reliability of equipment which establish a common basis for comparing and evaluating reliability predictions of related or competitive designs.

The FIDES methodology is an approach which is based on physics of failures and is supported by analyses of test data, feedback from operations and existing models. It is thus distinguished from other methods developed mainly from statistical interpretation of feedback from operations. In addition to taking electrical, mechanical and thermal over-stresses into consideration, the FIDES method also precisely takes account of the life profile. It is based on the consideration of three components, namely technology, process and use. The FIDES approach has been reported as a valid and useful tool [19] and though largely applied to aviation reliability calculations, it has also been used in other applications such as photovoltaic systems [20]. The FIDES method is used for the calculations presented herein.

A typical mission profile of a commercial aircraft is composed of a number of different operating modes or 'phases' such as ground operating, taxiing, take-off, cruising, landing and ground nonoperating or off mode. Depending on the aircraft type and mission, the duration of each phase can vary significantly. The phase details used in the calculations presented in this paper are shown in Table II. The total calendar hours used in these examples is 8,760 , representing a non-leap year. The $\Delta \mathrm{T}$ values are the maximum ambient temperature variation for the corresponding phase.

Table II: Aircraft Phase Durations and Temperature Variations

\begin{tabular}{|l|l|l|l|l|}
\hline Phase Name & $\begin{array}{l}\text { Equipment } \\
\text { On/Off }\end{array}$ & $\begin{array}{l}\text { Calendar time } \\
\text { (Hours) }\end{array}$ & $\begin{array}{l}\Delta \mathrm{T}\left({ }^{\circ} \mathrm{C}\right) \\
\text { during phase }\end{array}$ & $\begin{array}{l}\text { Maximum temperature } \\
\text { during cycling }\end{array}$ \\
\hline Gnd. Operating & ON & $2,622 \mathrm{~h}$ & 15 & $40^{\circ} \mathrm{C}$ \\
\hline Taxiing & ON & $312 \mathrm{~h}$ & 15 & $40^{\circ} \mathrm{C}$ \\
\hline Climb/Descent & ON & $1,240 \mathrm{~h}$ & 40 & $35^{\circ} \mathrm{C}$ \\
\hline Cruise & ON & $1,240 \mathrm{~h}$ & 0 & $5^{\circ} \mathrm{C}$ \\
\hline $\begin{array}{l}\text { Ground } \\
\text { Dormant }\end{array}$ & OFF & $3,346 \mathrm{~h}$ & 15 & $35^{\circ} \mathrm{C}$ \\
\hline
\end{tabular}


Combining the calculated component temperature variation per phase from the mission model information displayed in Fig. 9 with the phase delta temperatures in Table II, the FIT and MTBF values were calculated. These are shown in Table III.

Table III: FIDES Reliability Results in Non-pressurised and Pressurised Environments

\begin{tabular}{|l|l|l|l|l|}
\hline Environment & Sub-system & FIT & Flight Hours & Sub-system MTBF \\
\hline Non-pressurised & PCM Controller Board & 327.06 & 1154.52 & 865,669 \\
\hline & Driver Board & 326.35 & 1152.02 & 867,552 \\
\hline & Substrate & 215.05 & 759.13 & $1,316,741$ \\
\hline & TOTAL & & & 326,020 \\
\hline & PCM Controller Board & 108.06 & 381.45 & $2,620,079$ \\
\hline & Driver Board & 158.08 & 558.02 & $1,791,028$ \\
\hline & Substrate & 94.79 & 334.61 & $2,986,079$ \\
\hline & TOTAL & & & 784,434 \\
\hline
\end{tabular}

The MTBF is presented in Flight Hours. The scaling factor is defined in Equation (2).

$$
\lambda_{\mathrm{FH}}=\lambda_{\text {calendar }} \times \frac{\text { Calendar }}{\text { Mission }}=\lambda_{\text {calendar }} \times \frac{8760}{1240+1240}=\lambda_{\text {calendar }} \times 3.53
$$

The total MTBF figure for the entire system in a non-pressurised environment is 326,020 flight hours which exceeds the 150,000 requirement. The effect of each component type on the overall FIT is displayed in Fig. 12.
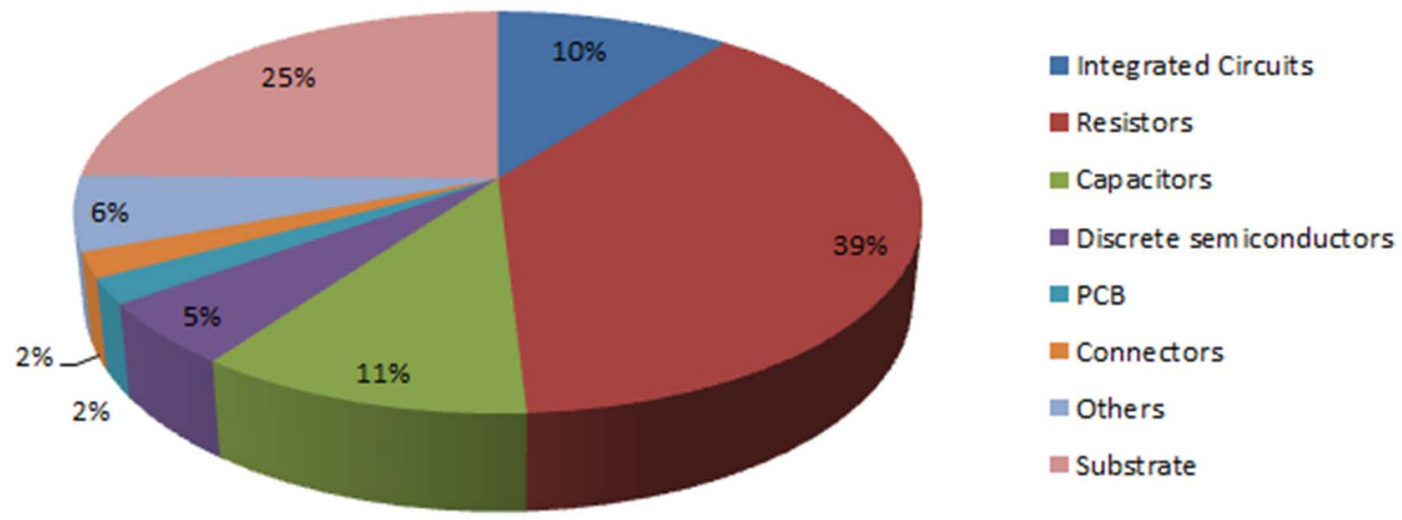

Fig. 12: Contribution by component type to FIT

The effects from each phase on the MTBF results when the PCM controller board is placed in a nonpressurised area are displayed in Fig. 13. As shown, the primary contribution is when the aircraft is climbing and descending. Also, Fig. 14 illustrates that the primary stress on the board is from thermal effects. This is consistent in both pressurised and non-pressurised surroundings. The results and conclusions are similar for the other PCM sub-systems. 


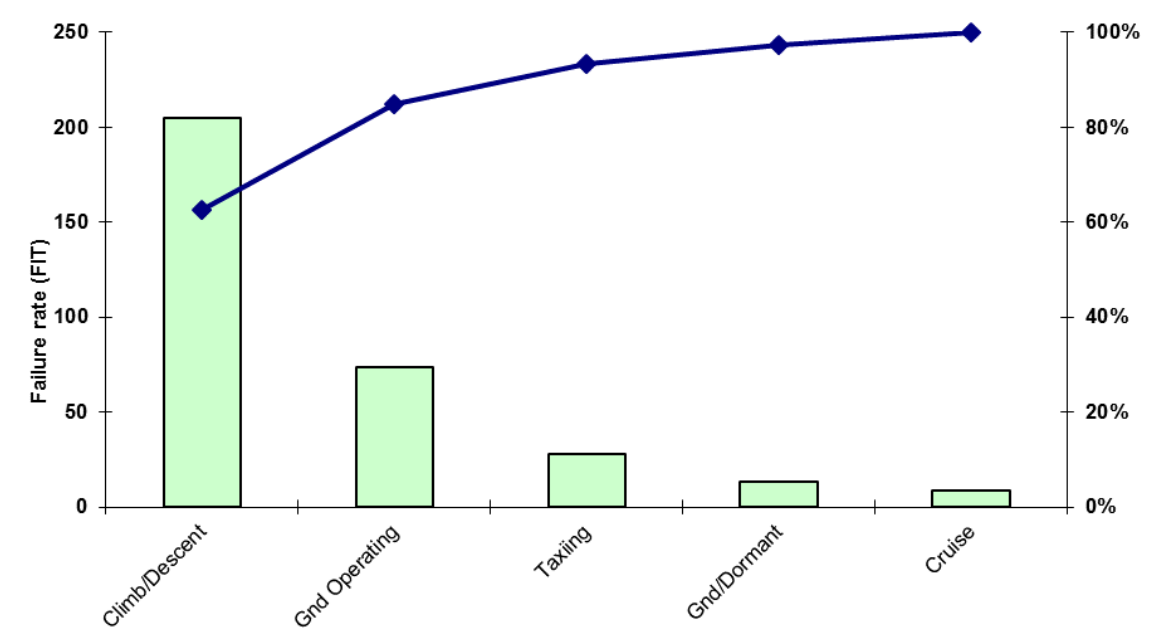

Fig. 13: Contribution by Phase to PCM Controller Board FIT in a non-pressurised environment

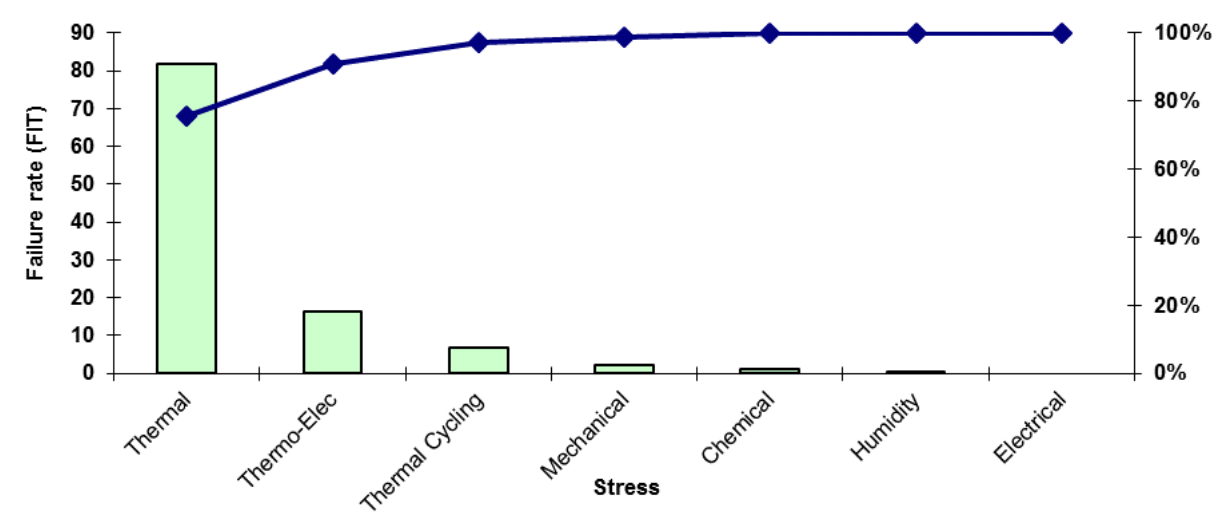

Fig. 14: Contribution by Stress

\section{Accelerated Mission Life-Test}

An accelerated test has been devised to determine the long-term reliability of the system. Accelerated lifetime testing is well-established terminology which refers to accelerating the rate at which physical processes are activated by increasing the operating temperature. However, this test does not modify temperature, but instead is a combined higher frequency/time dense mission profile. Using a test chamber with pressure and temperature variation, different flight phases are simulated. The pressure varies between a sea-level value of 1 bar and 0.145 bar which represents an altitude of 45,000 feet while the temperature changes from $+40^{\circ} \mathrm{C}$ to $-55^{\circ} \mathrm{C}$. The tests are run over short phase durations rather that those presented in Fig. 9 or Table 2. Two cycles of this profile are shown in Fig. 15.

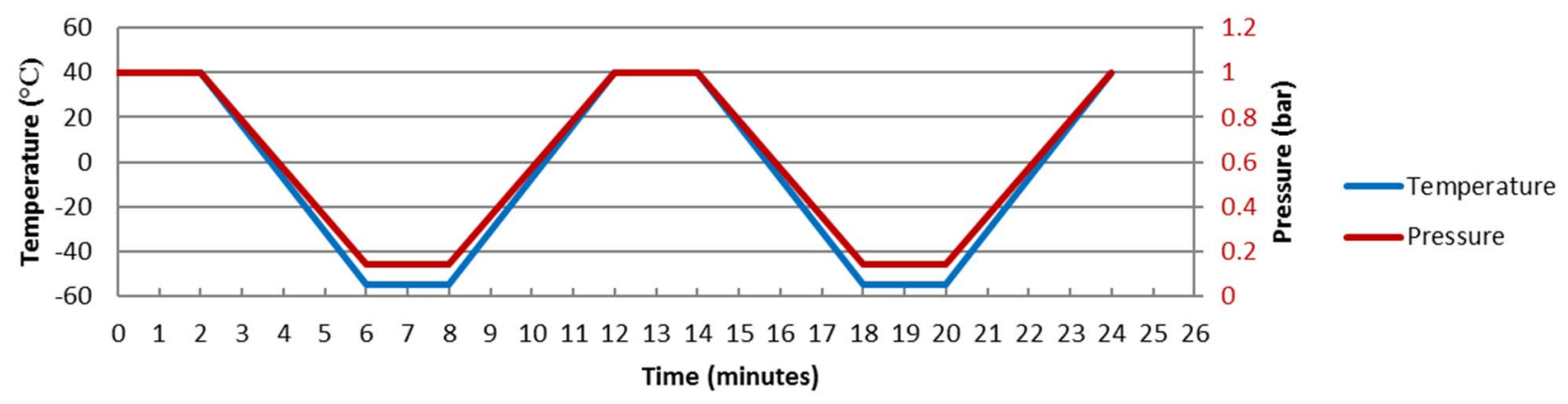

Fig. 15: Accelerated Mission Profile Test

The quantity of units, cycles and test duration are determined to verify a PCM lifetime greater than 150,000 flight hours. With a typical flight time of 75 minutes, this equates to 120,000 flights. Using 25 units and cycling over a 12-minute duration, a total test time of 40 days is required. 


\section{Conclusion}

This paper presents a power module designed for motor control in a More Electric Aircraft architecture. The function of this PCM in an electrical control unit system and details of the construction are presented. Test results verify the module operation. Simulation results of the module in a real-life aircraft during realistic missions display a notable improvement in power dissipation when SiC MOSFETs are used in place of Si IGBTs for the motor driver circuitry. The improved power density and efficiency can be used to increase switching frequency and reduce weight, which may result in even more benefit in terms of total airplane consumption. A preliminary theoretical analysis of the module reliability has been performed which confirms that the maximum reliability stress on the module is during the climbing and descending phases. Finally, a test devised to verify continued module operation for 150,000 flight hours has also been presented.

\section{References}

[1] J. Millan, P. Godignon, X. Perpinya, A. Perez-Tomas and J. Rebollo: A Survey of Wide Band Gap Power Semiconductor Devices, IEEE Transactions on Power Electronics, Vol. 29 no. 5, pp. 2155-2163

[2] J. Biela, M. Schweizer, S. Waffler, B. Wrzecionko, and J. W. Kolar: SiC versus Si-Evaluation of potentials for performance improvement of Inverter and DC-DC Converter Systems by SiC Power Semiconductors, IEEE Transactions on Industrial Electronics, Vol. 58 no. 7

[3] A. Elasser and T.P. Chow: Silicon Carbide Benefits and Advantages for Power Electronics Circuits and Systems, Proc. IEEE, Vol. 90, pp. 969-986

[4] Lixing Fu, Xuan Zhang, Scott, M., Chengcheng Yao, Jin Wang: The evaluation and application of wide bandgap power devices, Transportation Electrification Asia-Pacific (ITEC Asia-Pacific), 2014 IEEE Conference and Expo, pp. 1-5

[5] Haihong Qin, Bin Zhao, Xin Nie, Jiaopu Wen, Yangguang Yan: Overview of SiC power devices and its applications in power electronic converters, 8th IEEE Conference on Industrial Electronics and Applications (ICIEA), pp. 466-471

[6] Dimitrijev, S., Han, J., Haasmann, D., Moghadam, H.A., Aminbeidokhti, A.: Power-switching applications beyond silicon: The status and future prospects of $\mathrm{SiC}$ and $\mathrm{GaN}$ devices, 29th International Conference on Microelectronics Proceedings - MIEL, pp. 43-46

[7] Ong, A., Carr, J., Balda, J., Mantooth, A.: A Comparison of Silicon and Silicon Carbide MOSFET Switching Characteristics, 2007 IEEE Region 5 Technical Conference, pp. 273-377

[8] Tiefu Zhao, Jun Wang, Huang, A.Q., Agarwal, A.: Comparisons of SiC MOSFET and Si IGBT Based Motor Drive Systems, Industry Applications Conference, 2007. 42nd IAS Annual Meeting. Conference Record of the 2007 IEEE, pp. 331-335

[9] De, D., Castellazzi, A., Lopez-Arevalo, S., Lamantia, A.: SiC MOSFET based avionic power supply, Power Electronics, Machines and Drives (PEMD 2014), 7th IET International Conference on, pp. 1-6

[10] P. W. Wheeler, "The more electric aircraft: Why aerospace needs power electronics?" Power Electronics and Applications, 2009. EPE '09. 13th European Conference on, pp. 1-30

[11] FIDES Group, FIDES Guide 2009, Edition A

[12] Microsemi Corporation, Commercial Aviation Solutions Catalogue, 2016

[13] Microsemi Corporation, Military ProASIC3/EL Low Power Flash FPGAs with Flash*Freeze Technology Data Sheet, Rev 5

[14] Microsemi Corporation, APT40SM120 Datasheet, Rev B

[15] Microsemi Corporation, APT10SCE120 Datasheet, Rev B

[16] Infineon, 1EDI EiceDRIVERTM Compact Datasheet, Rev. 2.0

[17] Philips, Warren F.: Mechanics of Flight, John Wiley \& Sons Inc., 2004

[18] Sadraey, Mohammad: Aircraft Design: A Systems Engineering Approach, Wiley Publications, 2012

[19] Marin, J.J., Pollard, R.W.: Experience report on the FIDES reliability prediction method, Reliability and Maintainability Symposium, 2005. Proceedings. Annual, pp. 8-13

[20] De Leon-Aldaco, S.E., Calleja, H., Aguayo Alquicira, J.: Reliability and Mission Profiles of Photovoltaic Systems: A FIDES Approach, Power Electronics, IEEE Transactions on (Volume: 30, Issue: 5), pp. 2578 - 2586 